\title{
Trace elements in surface water of ombrotrophic bogs indicate the dissolution of dust particles generated by mining activities in northern
}

\author{
Alberta
}

\author{
SUNDAS A. BUTT, WILLIAM SHOTYK, FIORELLA \\ BARRAZA, NA CHEN, CHAD W. CUSS, LUKAS FROST, \\ IAIN GRANT-WEAVER, MUHAMMAD B. JAVED, ANDRII \\ OLEKSANDRENKO AND LEI PEI
}

University of Alberta

Presenting Author: sundas@ualberta.ca

Considerable volumes of dust are generated by open-pit mining for bitumen extraction in northern Alberta, Canada. The surface water of bogs can potentially dissolve the most reactive mineral phases of dust because of its low $\mathrm{pH}$ and abundant organic acids. Thus, the surface waters of peat bogs in industrial areas could be used as unique monitors, to determine the chemical reactivity and dissolution characteristics of dusts. The goal of this study is to determine whether elevated rates of dust deposition to peat bogs near bitumen mines have led to greater concentrations of trace elements (TEs) in their surface waters. To achieve this goal, it is essential to ensure that the TEs being measured in surface waters only represent dust dissolution and are not influenced by groundwaters or surface runoff.

The concentrations of TEs were measured in the dissolved fraction $(<0.45 \mu \mathrm{m})$ of surface waters collected from four peatlands near industry (JPH4, McK, McM, ANZ) and a control site (UTK) using ICP-MS. Surface waters near industry have elevated concentrations of $\mathrm{Li}, \mathrm{Fe}, \mathrm{Mn}, \mathrm{Ni}, \mathrm{Y}$, selected REE (Tm, $\mathrm{Dy}, \mathrm{Yb}, \mathrm{Sm})$, and $\mathrm{Pb}$ at 3 out of 4 sites, relative to the control location (UTK). Most concentrations were enriched $2 \mathrm{x}$ compared to $\mathrm{UTK}$, but $\mathrm{Li}, \mathrm{Mn}$, and $\mathrm{Rb}$ were enriched $>10 \mathrm{x}$. A vegetation survey at the site closest to industry (JPH4, $12 \mathrm{~km}$ from the midpoint between the two central bitumen upgraders) indicated that this peatland includes both ombrotrophic and minerotrophic zones. These zones were also identified based on the $\mathrm{pH}$ and concentrations of major ions in bog surface waters. At the next site closest to industry (McK, $25 \mathrm{~km}$ away), electrical conductivity and concentrations of chloride, $\mathrm{Na}$, and $\mathrm{K}$, all increased towards the highway, which suggests contributions from road salt runoff. Thus, at these two sites, the TE concentrations in surface waters are supplied not only from airborne dusts but also from groundwater and runoff. In contrast, the surface waters from McM (49 km) and ANZ (69 km) are ombrotrophic, so the elevated concentration of TEs in these waters can be attributed exclusively to dust dissolution. 